\title{
A method for calculating effective lifetime risk of radiation-induced cancer from screening mammography
}

\begin{abstract}
Purpose: To propose a method for evaluating the effective lifetime risk of radiation-induced cancer from screening mammography and to present initial data for the UK National Breast Screening Programme.

Material and methods: The imaging was undertaken using a Hologic Selenia full field digital mammographic unit. The proposed method utilises an ATOM phantom containing thermoluminescent dosimeters and a perspex-polyethylene breast phantom to measure organ doses during a standard four view screening mammogram. Effective dose was calculated and effective risk was modelled for a range of client ages. The total lifetime effective risk was then calculated for the UK national screening programme. Calculation of effective risk includes the radiation dose to examined and contralateral breasts in addition to other body organs; this is an advantage over the mean glandular dose.

Results: The contralateral breast, thyroid, thymus, brain, lung, salivary glands, and bone marrow all receive more than $1 \mu \mathrm{Gy}$ radiation dose during screening mammography. A major difference exists for total effective lifetime risk of radiation-induced cancer between clients with average and high breast cancer risk. Differences are attributed to the commencement age of screening and time interval between screens.
\end{abstract}

Conclusion: This study proposes a method to evaluate effective lifetime risk of radiation-induced cancer from screening mammography in order to compare different mammography screening programmes.

Key words: breast imaging, thermoluminescent dosimetry, digital mammography. 


\section{Introduction}

Medical imaging represents the major source of man-made ionizing radiation for people. ${ }^{1,2}$ In the United Kingdom (UK), mammography is the sixth largest source of ionizing radiation to the population from diagnostic imaging. ${ }^{3}$ However, the benefits of screening mammography are reported to outweigh the risks. ${ }^{4,5}$

Since the glandular tissue is the most radiosensitive component of the breast tissue, the risk of radiation induced cancer from mammography is generally related to mean glandular dose (MGD). ${ }^{6}$ MGD is utilised as a standard quantity in breast dosimetry and is recommended by the International Commission on Radiological Protection (ICRP), the National Council on Radiation Protection (NCRP), and the Institute of Physics and Engineering in Medicine (IPEM). MGD can be used as a parameter to evaluate the mammographic system performance, patient risk assessment, and different mammographic imaging techniques. ${ }^{7}$ Accordingly, it is of great interest to a large number of researchers. ${ }^{5,8-12}$

Surprisingly few investigators have considered the radiation dose received by body organs and tissues, other than the breast during mammography. They have investigated the dose to other tissues utilising mathematical models to simulate mammography. ${ }^{13-15}$ Direct measurement of the radiation dose to the skin overlying the thyroid has been investigated using thermoluminscent dosimeters (TLDs) during screening mammography. ${ }^{16}$ In the study by Whelan, McLean, and Poulos (16) they considered that the thyroid dose, which was $0.04 \mathrm{mGy}$, was insignificant compared to the $4 \mathrm{mGy}$ dose received by the breast. Hatziioannou and colleages ${ }^{17}$ also utilised TLDs, accommodated inside an upper body anthropomorphic lucite phantom for measurement of dose to the breast, sternum red bone marrow (SRBM), thyroid, liver, lung, stomach, and oesophagus during screening mammography. They found that the breast dose contributes over $98 \%$ of the overall effective dose. SRBM and thyroid receive a radiation dose between 0.41.27 and $0.05-0.17 \mathrm{mGy} / \mathrm{mAs}$, respectively, whereas the other organ doses were negligible. In summary, there is evidence to suggest that the radiation dose received by organs other than the breast requires further consideration as this dose and the risk associated with it is not captured by MGD. For a more thorough and accurate estimate of the risk from radiation during mammography, the dose to other organs should be taken into account. 
The internationally accepted method of estimating risk from an X-ray procedure is to use effective dose. Effective dose has enabled doses to be summed from whole and partial body exposure from external radiation of various types to estimate the risk of cancer development. Recently there is a new trend to replace effective dose by effective risk. ${ }^{18}$ Calculation of effective dose depends on tissue weighting factors which are regularly updated by ICRP based on the available evidence from epidemiological data. ${ }^{19}$ However, effective dose does not take into account an individual's age or reproductive capacity. The effective lifetime risk of developing cancer is less for people who have 20 years to live compared to those who have 60 years to live. Therefore, effective risk includes age, and gender lifetimeattributable risk of cancer incidence per unit equivalent dose. ${ }^{18}$

The lifetime attributable risk of radiation induced breast cancer from mammography has been calculated by Hendrick in $2010^{20}$ and more recently by Yaffe and Mainprize in 2011. ${ }^{21}$ However, these authors did not progress their work to include the effective lifetime risk of radiation induced cancer from screening mammography. Based upon the UK National Health Service Breast Screening Programme (NHSBSP), our study proposes a new method for the calculation of effective lifetime risk of radiation induced cancer during screening mammography for females across the screening age range (47-73 years average risk clients and 40-73 years high risk clients).

\section{Method}

This was an experimental approach for the calculation of effective lifetime risk of radiation-induced cancer from screening mammography for different client ages, from 40 to 73 years old. It required an accurate measurement of radiation dose received by the examined breast and other body tissues.

\section{A. Measurement of organ dose:}

280 Harshaw TLD-100H dosimeters (Thermo Scientific, USA) were placed inside a CIRS adult ATOM dosimetry phantom (CIRS Inc, Norfolk, Virginia, USA) to measure the absorbed radiation dose to tissues and organs during screening mammography (craniocaudal [CC] and mediolateral oblique [MLO] for each breast). TLDs- $100 \mathrm{H}$ were chosen because they have high sensitivity, wide dose 
range (1pGy to $10 \mathrm{~Gy}$ ), and low fading rate. ${ }^{22}$ In order to avoid any residual charge, the TLDs were annealed at $240^{\circ} \mathrm{C}$ for 10 minutes before use.

According to the European Commission ${ }^{23}$ the total uncertainty in dosimetric results by TLD should be less than $10 \%$. Therefore, the TLDs sensitivity and consistency were established. In terms of sensitivity, all TLDs were exposed three times and according to their average response they were divided into five groups. The sensitivity difference for each group was less than 3\%. For TLD consistency estimation, all TLDs were exposed and read three times with time intervals of around five days between the exposures then TLD responses were analysed using SPSS 20.0 (IBM, Armonk, New York, USA) to determine TLD consistency (Intraclass Correlation-Consistency). The calculated consistency was $99 \%$. Consequently, in our work, the total uncertainty of dose results was $4 \%$. The average background signal of three unexposed TLDs was subtracted from the readings of exposed TLDs. ${ }^{24}$ As described by Tootell, Szczepura, and Hogg $(2013)^{25}$, the TLDs were calibrated against Unfors Multi-O-Meter solid state detector (Billdal, Sweden) on three slabs $(1 \mathrm{~cm}$ thick each) of Perspex scatterer with beam quality the same as that which was used for dose measurement in the experiment, using the same mammography machine. Usually the calibration process is achieved for a complete batch because the calibration of each individual TLD is time consuming and shows minimal improvement in accuracy (the sensitivity difference of TLDs was less than 3\%). For greater precision, the doseTLD response curve was utilised to obtain the TLD calibration factor. ${ }^{26}$

A breast phantom described by Bouwman et al. (2013) ${ }^{27}$ was then used as standard breast. According to the design of this phantom, for simulating the standard breast, which is $53 \mathrm{~mm}$ thick, a $32.5 \mathrm{~mm}$ thick Poly Methyl Methacrylate (PMMA) and $20.5 \mathrm{~mm}$ thick polyethylene (PE) slabs were used; the PE slabs were placed at the top of the phantom. The shape and area of PMMA-PE phantom depends on the mammographic projection of the simulated breast. For the average breast in CC projection, the shape of compressed breast is approximately semicircular with $95 \mathrm{~mm}$ radius. However, because the pectoral muscle is included in MLO projection a rectangular phantom with $100 \mathrm{~mm} \times 150 \mathrm{~mm}$ was used with the required thickness of PMMA $(32.5 \mathrm{~mm})$ and polyethylene $(25.5 \mathrm{~mm}){ }^{28,29}$ 
The ATOM and breast phantoms were positioned on a Hologic Selenia full field digital mammography system (Bedford, USA) to simulate the real woman's position during screening mammography.

For MLO position simulation, firstly, the gantry was tilted $47^{\circ}$. This value of angulation is determined depending on ATOM phantom body contour. Secondly, the MLO phantom was centered on the detector in the chest wall side and the compression paddle was used to fix it in position. Thirdly, the ATOM phantom was arranged in contact with the breast phantom where the midpoint in the side of the breast phantom coincides with the centre point in the breast site on the ATOM phantom. The detector was placed against the ribs with its corner in the axilla.

The $\mathrm{CC}$ position was achieved with the X-ray beam perpendicular to the floor. Initially, the $\mathrm{CC}$ breast phantom was centred on the detector in the chest wall side and fixed in position by the compression paddle. The midpoint in the side of the breast phantom was arranged to coincide with the centre point in the breast site on the ATOM phantom, which faced the mammography system. ${ }^{30}$

Since automatic exposure control (AEC) is the most commonly used technique in screening mammography, it was adopted to expose the breast phantom. For each position the phantom was exposed three times and then averaged (CC and MLO for each breast) to minimise random error. TLDs were then collected and read in a Harshaw 3500 TLD reader (Thermo Scientific, USA). Using the manufacturer's TLD location map ${ }^{31}$, radiation absorbed dose of each organ was calculated by averaging the radiation dose values inside the organ. In addition to contralateral breast, doses received by 19 other organs were measured. The numbers of TLDs used for each organ are listed in (Table 1). The whole process was repeated three times on different days in order to examine the reproducibility of the data. 


\section{Table 1}

The number of TLDs utilised for dose measurement inside each organ.

\begin{tabular}{|c|c|c|c|}
\hline Organ & No. of TLDs & Organ & No. of TLDs \\
\hline Adrenal & 2 & Pancreas & 5 \\
\hline Brain & 11 & Pelvis BM & 17 \\
\hline Clavicle BM & 4 & Ribs BM & 18 \\
\hline Cranium BM & 4 & Scapulae BM & 16 \\
\hline C-spine BM & 2 & Spleen & 12 \\
\hline Gall bladder & 5 & Sternum BM & 4 \\
\hline Heart & 2 & Stomach & 14 \\
\hline Intestine & 15 & T/L spine BM & 8 \\
\hline Kidneys & 16 & Thymus & 4 \\
\hline Liver & 29 & Thyroid & 6 \\
\hline Lungs & 36 & Urinary Bladder (UB) & 16 \\
\hline Mandible BM & 6 & Contralateral breast & 8 \\
\hline Oesophagus & 3 & Salivary gland & 6 \\
\hline Ovaries & 2 & Uterus & 9 \\
\hline
\end{tabular}

\section{B. Estimation of examined breast dose:}

MGD was calculated using the method recommended by IPEM (Report 89) ${ }^{32}$ and using the following equation:

$$
M G D=K \cdot g_{53 .} \cdot c_{53 .} . S
$$

Where $K$ is the entrance air kerma for the phantom, $g_{53}$ is a factor to convert the incident air kerma to MGD for $53 \mathrm{~mm}$ thick standard breast, $c_{53}$ is a conversion factor which allows for the glandularity of $53 \mathrm{~mm}$ thick standard breast, $s$ is the spectral correction factor. The values for the above factors are listed in the same report for each half-value layer (HVL).

In our study the HVL of the mammographic X-ray beam was assessed according to the procedure described by Moore et al. (2005) $)^{32}$ in IPEM report 89. An Unfors solid state dosimeter and high purity aluminum foils of thickness ranging from $0.1 \mathrm{~mm}$ to $0.6 \mathrm{~mm}$ were used. The foils were placed infront of the X-ray beam window with the compression paddle midway between the foils and detector. Then, as recommended by the European Commission ${ }^{23}$, the HVL was graphically derived by an interpolation method. This was done by plotting the detector 
readings algorithms against the relevant foil thickness. For mammographic X-ray beams used in CC and MLO views, the estimated values of HVL were 0.4 and $0.5 \mathrm{~mm} \mathrm{Al}$, respectively.

\section{Radiation effective risk estimation:}

The effective risk was calculated by using the equation described by Brenner (2009). ${ }^{18}$

$$
R=\sum r_{T} H_{T}
$$

Where $R$ is the effective risk, $r_{T}$ is the lifetime cancer risk for tissue $T$ per unit equivalent dose of that tissue, and $H_{T}$ is the equivalent dose for tissue $T$.

The attributable lifetime cancer risk of different tissues $\left(r_{T}\right)$ are taken from BEIR VII - Phase 2 report of National Academy of Sciences. ${ }^{33}$ Because these values are presented for each decade of female age (see Table 2), they were plotted against age to obtain the value for each year of female life see (Figure 1) for the breast. A line for best fit was created $\left(y=0.13 x^{2}-19.074 x+703.09, R^{2}=0.9959\right)$ to determine risk for years 41-49, 51-59, 61-69, and 71-79 inclusive. The same method was used for each type of tissue.

\section{Table 2}

Lifetime attributable risk of radiation induced cancer for tissues which received radiation dose during screening mammography for each decade of female age as listed in Table 12D-1 of the 2006 BEIR-VII report. ${ }^{33}$

\begin{tabular}{|l|c|c|c|c|c|}
\hline \multirow{2}{*}{ Tissue } & \multicolumn{5}{|c|}{ Risk coefficient (cases /10,000 persons/Gy) at different ages } \\
\cline { 2 - 6 } & 40 & 50 & 60 & 70 & 80 \\
\hline Breast & 141 & 70 & 31 & 12 & 4 \\
\hline Stomach & 35 & 32 & 27 & 19 & 11 \\
\hline Liver & 10 & 9 & 7 & 5 & 2 \\
\hline Lung & 240 & 230 & 201 & 147 & 77 \\
\hline Thyroid & 14 & 4 & 1 & 0.3 & 0 \\
\hline Other & 181 & 148 & 109 & 68 & 30 \\
\hline
\end{tabular}




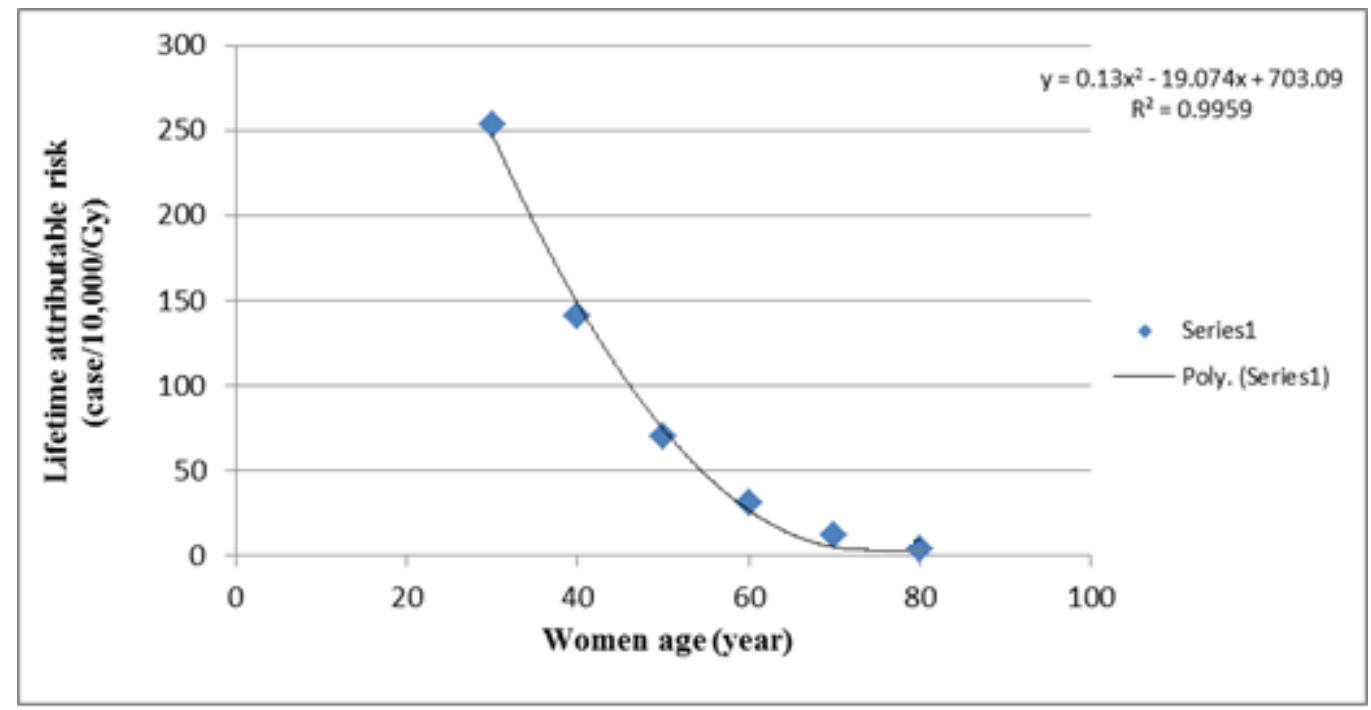

Figure 1. Lifetime attributable risk of radiation induced cancer in breast tissue for women aged $30-80$ years.

\section{Results}

Examined breast MGD along with radiation absorbed dose for other 20 organs, from one screening visit, are recorded in (Table 3). It provides evidence that some organs did not receive a radiation dose during screening mammography. However, other organs received a radiation dose ranging from 0.006 to $26.6 \mu \mathrm{Gy}$. 
Table 3

Organ radiation dose from one screening visit (4 views).

\begin{tabular}{|c|c|c|c|c|c|}
\hline & Organ & $\begin{array}{c}\text { Dose } 1 \\
(\mu \mathrm{Gy})\end{array}$ & $\begin{array}{l}\text { Dose } 2 \\
(\mu \mathrm{Gy})\end{array}$ & $\begin{array}{c}\text { Dose } 3 \\
(\mu \mathrm{Gy})\end{array}$ & $\begin{array}{l}\text { Average dose } \\
\text { (SD) }(\mu \mathrm{Gy})\end{array}$ \\
\hline Brain & & 1.312 & 1.108 & 1.538 & $1.320(0.21)$ \\
\hline Salivary & glands & 3.825 & 2.714 & 2.143 & $2.894(0.86)$ \\
\hline Thyroid & & 10.421 & 9.527 & 8.573 & $9.507(0.92)$ \\
\hline Oesopha & & 0.340 & 0.221 & 0.245 & $0.269(0.06)$ \\
\hline Thymus & & 3.180 & 2.278 & 2.062 & $2.506(0.59)$ \\
\hline Heart & & 0.488 & 0.373 & 0.296 & $0.386(0.10)$ \\
\hline Lung & & 2.942 & 2.611 & 2.457 & $2.670(0.25)$ \\
\hline Liver & & 0.477 & 0.564 & 0.461 & $0.501(0.06)$ \\
\hline Gall blac & & 0.103 & 0.054 & 0.055 & $0.071(0.03)$ \\
\hline Adrenal & & 0.302 & 0.541 & 0.350 & $0.398(0.13)$ \\
\hline Kidney & & 0.086 & 0.074 & 0.103 & $0.088(0.01)$ \\
\hline Spleen & & 0.128 & 0.027 & 0.018 & $0.058(0.06)$ \\
\hline Pancreas & & 0.005 & 0.004 & 0.008 & $0.006(0.00)$ \\
\hline Stomach & & 0.315 & 0.284 & 0.492 & $0.363(0.11)$ \\
\hline Intestine & & 0.000 & 0.000 & 0.000 & $0.000(0.00)$ \\
\hline & Cranium & 2.552 & 1.541 & 2.439 & $2.177(0.55)$ \\
\hline & Mandible & 3.325 & 2.714 & 2.643 & $2.894(0.37)$ \\
\hline & C-spine & 1.020 & 0.524 & 0.541 & $0.695(0.28)$ \\
\hline & Clavicle & 10.408 & 11.652 & 12.963 & $11.674(1.28)$ \\
\hline Bone & Scapulae & 0.298 & 0.276 & 0.282 & $0.285(0.01)$ \\
\hline $\begin{array}{l}\text { Marrow } \\
\text { (BM) }\end{array}$ & Sternum & 14.092 & 15.378 & 16.021 & $15.164(0.98)$ \\
\hline & Ribs & 3.466 & 3.172 & 3.043 & $3.227(0.22)$ \\
\hline & $\mathrm{T} / \mathrm{L}$ spine & 0.256 & 0.100 & 0.137 & $0.164(0.08)$ \\
\hline & Pelvis & 0.000 & 0.000 & 0.000 & $0.000(0.00)$ \\
\hline & Total BM dose $(63.5 \%)^{*}$ & 1.420 & 1.276 & 1.365 & $1.353(0.07)$ \\
\hline Urinary & ladder & 0.000 & 0.000 & 0.000 & $0.000(0.00)$ \\
\hline Uterus & & 0.000 & 0.000 & 0.000 & $0.000(0.00)$ \\
\hline Ovaries & & 0.000 & 0.000 & 0.000 & $0.000(0.00)$ \\
\hline Contrala & eral breast & 25.941 & 28.705 & 25.102 & $26.583(1.89)$ \\
\hline Examine & breast (MGD) & 2681.000 & 2674.000 & 2685.000 & $2680.000(5.57)$ \\
\hline
\end{tabular}

${ }^{*}$ This percent represents the portion of bone marrow $(B M)$ received radiation dose during mammography. It is adapted from ICRP report 70 (1995) and it is distributed as $0.8 \%$ in clavicle, $7.6 \%$ in cranium, 3.9\% in C-spine, T/L spine (28.4\%), $0.8 \%$ in mandible, $16.1 \%$ in ribs, $2.8 \%$ in scapula, and $3.1 \%$ in sternum. ${ }^{34}$ 
The effective dose in $\mu \mathrm{Sv}$ was calculated for one screening event (four views) depending on the latest tissue weighting factors that have been recommended by ICRP (2007). ${ }^{35}$ The generated data of this calculation are presented in (Table 4) together with absorbed dose of individual organs.

\section{Table 4}

Tissue weighting factor, mean organ dose, and weighted dose used to calculate female effective dose $(E D)$ from one four-view screening mammography procedure. Standard deviations $(s d)$ are in parenthesis.

\begin{tabular}{|c|c|c|c|}
\hline Organ & $\begin{array}{l}\text { Tissue weighting } \\
\text { factor }\left(w_{T}\right)\end{array}$ & $\begin{array}{l}\text { Mean Organ Dose } \\
(s d)(\mu \mathrm{Gy})\end{array}$ & $\begin{array}{l}\text { Weighted } \\
\text { dose }(\mu \mathrm{Sv})\end{array}$ \\
\hline Bone marrow & 0.12 & $1.353(0.07)$ & 0.162 \\
\hline Colon & 0.12 & $0.000(0.00)$ & 0.000 \\
\hline Lung & 0.12 & $2.670(0.25)$ & 0.320 \\
\hline Stomach & 0.12 & $0.363(0.11)$ & 0.044 \\
\hline Ovaries & 0.08 & $0.000(0.00)$ & 0.000 \\
\hline Bladder & 0.04 & $0.000(0.00)$ & 0.000 \\
\hline Oesophagus & 0.04 & $0.269(0.06)$ & 0.011 \\
\hline Liver & 0.04 & $0.501(0.06)$ & 0.020 \\
\hline Thyroid & 0.04 & $9.507(0.92)$ & 0.380 \\
\hline Brain & 0.01 & $1.320(0.21)$ & 0.013 \\
\hline Salivary glands & 0.01 & $2.894(0.86)$ & 0.029 \\
\hline Other & 0.12 & $0.390(0.08)$ & 0.047 \\
\hline Contralateral breast & 0.12 & $26.583(1.89)$ & 3.190 \\
\hline $\begin{array}{l}\text { Examined breast (MGD) } \\
\text { (2 view) }\end{array}$ & 0.12 & $2680.000(5.57)$ & 321.6 \\
\hline \multicolumn{4}{|c|}{ Mean ED $(S D)=325.816(0.67)(\mu S v)$} \\
\hline
\end{tabular}

Because of the continuous decline in human tissue radio-sensitivity with age (Figure1), the effective risk from screening mammography reduces with increasing age (Table 5). The amount of this reduction depends on tissue type. 


\section{Table 5}

Radiation effective risk of one screening mammography event (4view) for female aged 40-73years.

\begin{tabular}{|c|c|c|c|c|c|c|c|c|}
\hline \multirow{2}{*}{$\begin{array}{l}\text { Age } \\
\text { (year) }\end{array}$} & \multicolumn{7}{|c|}{ Cancer incidence in different tissues (case/106) } & \multirow{2}{*}{$\begin{array}{c}\text { Effective risk } \\
\qquad(s d) \\
\left(\text { case } / 10^{6}\right)\end{array}$} \\
\hline & Stomach & Liver & Lung & Thyroid & Other & $\begin{array}{c}\text { Examined } \\
\text { breast }\end{array}$ & $\begin{array}{c}\text { Contralateral } \\
\text { breast }\end{array}$ & \\
\hline 40 & 0.001 & 0.000 & 0.065 & 0.012 & 0.015 & 39.699 & 0.394 & $40.187(0.05)$ \\
\hline 41 & 0.001 & 0.000 & 0.065 & 0.011 & 0.015 & 37.409 & 0.371 & $37.873(0.05)$ \\
\hline 42 & 0.001 & 0.000 & 0.065 & 0.009 & 0.015 & 35.189 & 0.349 & $35.629(0.05)$ \\
\hline 43 & 0.001 & 0.000 & 0.065 & 0.008 & 0.014 & 33.039 & 0.328 & $33.455(0.05)$ \\
\hline 44 & 0.001 & 0.000 & 0.064 & 0.007 & 0.014 & 30.958 & 0.307 & $31.352(0.04)$ \\
\hline 45 & 0.001 & 0.000 & 0.064 & 0.006 & 0.014 & 28.947 & 0.287 & $29.320(0.04)$ \\
\hline 46 & 0.001 & 0.000 & 0.064 & 0.006 & 0.014 & 27.005 & 0.268 & $27.358(0.04)$ \\
\hline 47 & 0.001 & 0.000 & 0.063 & 0.005 & 0.013 & 25.134 & 0.249 & $25.466(0.03)$ \\
\hline 48 & 0.001 & 0.000 & 0.063 & 0.004 & 0.013 & 23.332 & 0.231 & $23.645(0.03)$ \\
\hline 49 & 0.001 & 0.000 & 0.062 & 0.004 & 0.013 & 21.599 & 0.214 & $21.894(0.03)$ \\
\hline 50 & 0.001 & 0.000 & 0.062 & 0.003 & 0.012 & 19.937 & 0.198 & $20.213(0.03)$ \\
\hline 51 & 0.001 & 0.000 & 0.061 & 0.003 & 0.012 & 18.344 & 0.182 & $18.603(0.03)$ \\
\hline 52 & 0.001 & 0.000 & 0.060 & 0.003 & 0.012 & 16.820 & 0.167 & $17.063(0.02)$ \\
\hline 53 & 0.001 & 0.000 & 0.059 & 0.002 & 0.012 & 15.367 & 0.152 & $15.594(0.02)$ \\
\hline 54 & 0.001 & 0.000 & 0.059 & 0.002 & 0.011 & 13.983 & 0.139 & $14.195(0.02)$ \\
\hline 55 & 0.001 & 0.000 & 0.058 & 0.002 & 0.011 & 12.668 & 0.126 & $12.866(0.02)$ \\
\hline 56 & 0.001 & 0.000 & 0.057 & 0.002 & 0.011 & 11.424 & 0.113 & $11.608(0.02)$ \\
\hline 57 & 0.001 & 0.000 & 0.056 & 0.001 & 0.010 & 10.249 & 0.102 & $10.420(0.01)$ \\
\hline 58 & 0.001 & 0.000 & 0.055 & 0.001 & 0.010 & 9.144 & 0.091 & $9.302(0.01)$ \\
\hline 59 & 0.001 & 0.000 & 0.054 & 0.001 & 0.010 & 8.108 & 0.080 & $8.255(0.01)$ \\
\hline 60 & 0.001 & 0.000 & 0.053 & 0.001 & 0.009 & 7.142 & 0.071 & $7.278(0.01)$ \\
\hline 61 & 0.001 & 0.000 & 0.052 & 0.001 & 0.009 & 6.246 & 0.062 & $6.371(0.01)$ \\
\hline 62 & 0.001 & 0.000 & 0.051 & 0.001 & 0.009 & 5.419 & 0.054 & $5.535(0.01)$ \\
\hline 63 & 0.001 & 0.000 & 0.049 & 0.001 & 0.008 & 4.663 & 0.046 & $4.769(0.01)$ \\
\hline 64 & 0.001 & 0.000 & 0.048 & 0.001 & 0.008 & 3.976 & 0.039 & $4.073(0.01)$ \\
\hline 65 & 0.001 & 0.000 & 0.047 & 0.001 & 0.008 & 3.358 & 0.033 & $3.447(0.01)$ \\
\hline 66 & 0.001 & 0.000 & 0.045 & 0.000 & 0.007 & 2.810 & 0.028 & $2.892(0.01)$ \\
\hline 67 & 0.001 & 0.000 & 0.044 & 0.000 & 0.007 & 2.332 & 0.023 & $2.408(0.01)$ \\
\hline 68 & 0.001 & 0.000 & 0.042 & 0.000 & 0.007 & 1.924 & 0.019 & $1.993(0.01)$ \\
\hline 69 & 0.001 & 0.000 & 0.041 & 0.000 & 0.006 & 1.585 & 0.016 & $1.649(0.00)$ \\
\hline 70 & 0.001 & 0.000 & 0.039 & 0.000 & 0.006 & 1.316 & 0.013 & $1.376(0.00)$ \\
\hline 71 & 0.001 & 0.000 & 0.038 & 0.000 & 0.006 & 1.116 & 0.011 & $1.172(0.00)$ \\
\hline 72 & 0.001 & 0.000 & 0.036 & 0.000 & 0.005 & 0.987 & 0.010 & $1.039(0.00)$ \\
\hline 73 & 0.001 & 0.000 & 0.034 & 0.000 & 0.005 & 0.927 & 0.009 & $0.976(0.00)$ \\
\hline
\end{tabular}


The total radiation effective risk, during a female's lifetime, is generally related to the age of screening commencement and time interval between the successive screens. Data for 'average' and 'high risk' NHSBSP clients are presented in (Table $6)$.

\section{Table 6}

Total effective risk (during woman life) of screening mammography according to UK national mammography screening programme.

\begin{tabular}{|c|c|c|c|c|c|}
\hline Country & $\begin{array}{c}\text { Level of } \\
\text { breast } \\
\text { cancer risk }\end{array}$ & Age range & $\begin{array}{c}\text { Time interval } \\
\text { between two } \\
\text { screens }\end{array}$ & $\begin{array}{c}\text { Total } \\
\text { number of } \\
\text { screens }\end{array}$ & $\begin{array}{c}\text { Effective } \\
\text { Risk }(s d) \\
\left(\text { case } / 10^{6}\right)\end{array}$ \\
\hline $\begin{array}{c}\text { UK } \\
(\mathrm{NHSBSP})^{36}\end{array}$ & average & $47-73$ & 3 years & 9 & $\begin{array}{c}93.283 \\
(0.13)\end{array}$ \\
\hline $\begin{array}{c}\text { UK } \\
(\mathrm{NHSBSP})^{36}\end{array}$ & high & $40-73$ & 1 year & 34 & $\begin{array}{c}489.274 \\
(0.67)\end{array}$ \\
\hline
\end{tabular}

\section{Discussion}

The objective of screening mammography is to detect breast cancer early when treatment and recovery are more likely to be successful. However, since the introduction of screening mammography there has been great debate about the risks versus benefits. In this context, Jin $(2014)^{37}$ reported the possible disadvantages of screening mammography, other than the radiation risk. These drawbacks were: firstly, the false negative which is mammography's inability to detect all breast cancers; secondly, mammography false positive (wrong diagnosis) which results in time wasted in extra examinations and undesired anxiety; thirdly, over diagnosis, the treatment of low risk breast cancers which would not cause health problems.

To understand the radiation risk associated with mammography many researchers have focused on screening mammography. The majority of researchers used mean glandular dose as a parameter to quantify the radiation risk. In contrast others utilised women-years of life lost due to radiation induced cancer from screening mammography. Our work uses the effective risk of radiation induced cancer as a parameter to assess mammography radiation risk. The method of effective risk 
calculation is relatively easy to perform, takes age into account and generates data that are more understandable to the general public when compared to MGD.

However, there are several limitations with our method. Firstly, a single size body phantom was used and this limits the generalisability of our calculations to average size women only. Secondly, there will be error associated with the fitting process $\left(y=0.13 x^{2}-19.074 x+703.09\right)$ of life time attributable risk to adjust for unpublished data for each year of the life. Thirdly, only the average female breast has been considered in our study. Other breast thicknesses and compositions were not considered, this should be addressed in future research.

Female breasts have different sizes and densities, the latter changes with age. Consequently our method can be extended by using different sizes of human body phantoms and breast phantoms of different thicknesses and densities. For instance, to simulate small dense breast, which has a $20 \mathrm{~mm}$ thickness and $97 \%$ density, a 20 mm PMMA have to be used. On the contrary, $37.5 \mathrm{~mm}$ PMMA and $62.5 \mathrm{~mm}$ PE can be utilised to simulate thick fatty breast that has $100 \mathrm{~mm}$ thickness and $3 \%$ glandularity ${ }^{(27)}$.

The comparison of different categories of NHSBSP, in terms of total effective risk, (Table 6) illustrates that the total effective risk of high breast cancer risk client is about 5 times more than that of average risk client. NHSBSP was used to illustrate data arising from our method, we propose that our method be applied to different screening programmes world-wide and also different mammography machines so that effective risk comparisons can be made.

\section{Conclusion}

A new method has been developed to quantify the risk of radiation induced cancer (effective risk) from screening mammography. This method can be used to compare international mammography screening programmes. High breast cancer risk clients have higher effective risk from radiation than those with average breast cancer risk. Effective risk should be taken into account when mammography screening programmes have their effectiveness assessed. 


\section{References:}

1. Olarinoye IO, Sharifat I. A protocol for setting dose reference level for medical radiography in Nigeria: a review. Bayero Journal of Pure and Applied Sciences. 2010;3(1):138-41.

2. Zenone F, Aimonetto S, Catuzzo P, Peruzzo Cornetto A, Marchisio P, Natrella M, et al. Effective dose delivered by conventional radiology to Aosta Valley population between 2002 and 2009. The British journal of radiology. 2012;85(1015):e330-8.

3. Hart D, Wall BF, Hillier MC, Shrimpton PC. Frequency and collective dose for medical and dental $x$-ray examinations in the UK, 2008. 2010 HPA-CRCE-012.

4. Tabár L, Vitak B, Chen TH-H, Yen AM-F, Cohen A, Tot T, et al. Swedish two-county trial: impact of mammographic screening on breast cancer mortality during 3 decades. Radiology. 2011;260(3):658-63.

5. Dellie ST, Rao ADP, Admassie D, Meshesha AZ. Evaluation of Mean Glandular Dose during Diagnostic Mammography Examination for Detection of Breast Pathology, in Ethiopia. OMICS Journal of Radiology. 2013;01(04).

6. Myronakis ME, Zvelebil M, Darambara DG. Normalized mean glandular dose computation from mammography using GATE: a validation study. Phys Med Biol. 2013;58(7):2247-65.

7. Säbel $M$, Aichinger $H$. Recent development in breast imaging. Pysics in medicine and biology. 1996;41(3):315-68.

8. Geeraert N, Klausz R, Muller S, Bloch I, Bosmans H, editors. Breast characteristics anddisimetric data in $\mathrm{X}$ ray mammography - a large sample worldwide survey International Conference on Radiation Protection in Medicine; 2012; Germany.

9. Di Maria S, Barros S, Bento J, Teles P, Figueira C, Pereira M, et al. TLD measurements and Monte Carlo simulations for glandular dose and scatter fraction assessment in mammography: A comparative study. Radiation Measurements. 2011;46(10):1103-8.

10. Dong SL, Chu TC, Lan GY, Lin YC, Yeh YH, Chuang KS. Development of an adjustable model breast for mammographic dosimetry assessment in Taiwanese women. AJR American journal of roentgenology. 2011;196(4):W476-81.

11. Nsiah-Akoto I, Andam AB, Adisson EK, Forson AJ. Preliminary studies into the determination of mean glandular dose during diagnostic mammography procedure in Ghana. Research Journal of Applied Sciences, Engineering and Technology. 2011;3(8):720-4.

12. Tsai HY, Chong NS, Ho YJ, Tyan YS. Evaluation of depth dose and glandular dose for digital mammography. Radiation Measurements. 2010;45(3-6):726-8.

13. Leidens M, Goes E, Nicolluci P. Use of Monte Carlo method to determine radiation dose to organs and tissues from mammography. Medical physics. 2013;40(6):139.

14. Sechopoulos I, Hendrick RE. Mammography and the risk of thyroid cancer. AJR American journal of roentgenology. 2012;198(3):705-7.

15. Sechopoulos I, Suryanarayanan S, Vedantham S, D'Orsi CJ, Karellas A. Radiation dose to organs and tissues from mammography: Monte Carlo and phantom study. Radiology. 2008;246(2):434-43.

16. Whelan C, McLean D, Poulos A. Investigation of thyroid dose due to mammography. Australasian radiology. 1999;43(3):307-10.

17. Hatziioannou KA, Psarrakos K, Molyvda-Athanasopoulou E, Kitis G, Papanastassiou E, Sofroniadis I, et al. Dosimetric considerations in mammography. European Radiology. 2000;10(7):1193-6.

18. Brenner DJ. We can do better than effective dose for estimating or comparing low-dose radiation risks. Ann ICRP. 2012;41(3-4):124-8.

19. NuclearEnergyAgency(NEA). Evolution of ICRP Recommendations 1977, 1990 and 2007: OECD; 2011 [cited 2014]. Available from: http://www.oecd-nea.org/rp/reports/2011/nea6920-ICRPrecommendations.pdf. 
20. Hendrick RE. Radiation doses and cancer risks from breast imaging studies. Radiology. 2010;257(1):246-53.

21. Yaffe MJ, Mainprize JG. Risk of radiation-induced breast cancer from mammographic screening. Radiology. 2011;258(1):98-105.

22. ThermoScientific. High Sensitivity LIF: $\mathrm{Mg}, \mathrm{Cu}, \mathrm{P}$ Thermoluminescent Dosimetry Materials, Chips - See more at: http://www.thermoscientific.com/en/product/high-sensitivity-lif-mg-cu-pthermoluminescent-dosimetry-materials-1.html\#sthash.L5oYrcjO.dpuf 2015.

23. EuropeanCommission. European protocol on dosimetry in mammography. 1996.

24. Sulieman A, Theodorou K, Vlychou M, Topaltzikis T, Kanavou D, Fezoulidis I, et al. Radiation dose measurement and risk estimation for paediatric patients undergoing micturating cystourethrography. The British journal of radiology. 2007;80(957):731-7.

25. Tootell AK, Szczepura KR, Hogg P. Optimising the number of thermoluminescent dosimeters required for the measurement of effective dose for computed tomography attenuation correction data in SPECT/CT myocardial perfusion imaging. Radiography. 2013;19(1):42-7.

26. Shirazi A, Mahdavi SR, Khodadadee A, Ghaffory M, Mesbahi A. Monte Carlo simulation of TLD response function: Scattered radiation fi eld application. Reports of Practical Oncology \& Radiotherapy. 2008;13(1):23-8.

27. Bouwman RW, Diaz O, van Engen RE, Young KC, den Heeten GJ, Broeders MJ, et al. Phantoms for quality control procedures in digital breast tomosynthesis: dose assessment. Phys Med Biol. 2013;58(13):4423-38.

28. Wang F-L, Chen F, Yin H, Xu N, Wu X-X, Ma J-J, et al. Effects of Age, Breast Density and Volume on Breast Cancer Diagnosis: A Retrospective Comparison of Sensitivity of Mammography and Ultrasonography in China's Rural Areas. Asian Pacific Journal of Cancer Prevention. 2013;14(4):2277-82.

29. Diffey JL. Development and Evaluation of a Method for Measuring Breast Density (Unpublished PhD thesis). Manchester: University of Manchester; 2012.

30. Kopans, D. B. Breast imaging (Third ed.). Philadelphia: Lippincott Williams \& Wilkin (2007).

31. CIRSTissueSimulationandPhantomTechnology. ATOM dosimetry phantoms models 701-706. Virginia: CIRS, Inc; 2012.

32. Moore AC, Dance DR, Evans DS, Lawinski CP, Pitcher EM, Rust A, et al. The commissioning and routine testing of mammographic $\mathrm{X}$-ray systems. York: Institute of physics and engineering in medicin; 2005.

33. NationalAcademyofSciences. Health Risks from Exposure to Low Levels of Ionizing Radiation: BEIR VII - Phase 2. Washington: National Academies Press; 2006.

34. InternationalCommissiononRadiologicalProtectionICRP. Basic anatomical and physiological data: The skeleton (publication 70). Annals of the ICRP. 1995;25(2):1-80.

35. InternationalCommissiononRadiologicalProtection[ICRP]. The 2007 Recommendations of the International Commission on Radiological Protection. ICRP publication 103. Annals of the ICRP. 2007;37(2-4):1-332.

36. National Health Services Breast Screeninig Program [NHSBSP]. (2014). NHS breast screening programme extending the screening age range. Retrieved 3rd September, 2014, from http://www.cancerscreening.nhs.uk/breastscreen/rollout-age-extension-leaflet.pdf.

37. Jin J. Breast Cancer Screening: Benefits and Harms. JAMA. 2014; 312(23):2585. 